\title{
Practitioners should embrace, not ignore, health apps
}

\author{
Eamonn Hickey medical student, Brian McMillan academic clinical fellow in primary care, Caroline \\ Mitchell senior clinical lecturer
}

Academic Unit of Primary Medical Care, University of Sheffield, Northern General Hospital, Sheffield S5 7AU, UK

We are currently exploring two of the concerns raised by Husain and Spence - the regulation of health apps and evidence for their effectiveness. ${ }^{1}$ Android and iOS app stores currently contain more than 100000 health apps, and the number is constantly increasing. ${ }^{2}$ The NHS Choices Health Apps Library contains verified apps with trusted information that are clinically safe and comply with data protection standards. ${ }^{3}$ We have adapted the National Institute for Health and Care Excellence behaviour change guidance into a preliminary quality assessment framework for mobile apps aimed at behaviour change. ${ }^{4}$

When this framework was applied to the NHS apps library, we found that the apps tended to focus on initiating behaviour change rather than maintaining change or preventing relapse; very few have any form of evaluation of effectiveness planned, even though many collected outcome data through tracking and self reporting. App developers and researchers should try to fill these gaps, and clinicians could help to drive this change.

Our ongoing update of a systematic review shows that effectiveness depends on long term adherence. ${ }^{5}$ Some short term effects are seen, but if the intervention is not adhered to in the longer term the impact is diluted. Apps were most successful when combined with measures such as reminder phone calls or regular one to one appointments, rather than standalone treatment.
Mobile apps have potential for both primary care practitioners and patients. In a time of increasing pressures on the NHS, value is placed on prevention over symptom management. The world of the worried well would be less likely if this new technology is embraced rather than ignored by practitioners, and if we work in partnership with patients, researchers, and designers to help evaluate how this technology can improve the health of our patients in the future.

Competing interests: None declared.

Full response at: www.bmj.com/content/350/bmj.h1887/rr-2.

Husain I, Spence D. Can healthy people benefit from health apps? BMJ 2015;350:h1887. (14 April).

2 Boxall A. 2014 is the year of health and fitness apps, says Google. Digital Trends 2014. www.digitaltrends.com/mobile/google-play-store-2014-most-downloaded-apps/.

3 NHS Choices Health Apps Library. Review process. http://apps.nhs.uk/review-process/

4 National Institute for Health and Care Excellence. Behaviour change: individual approaches. 2014. www.nice.org.uk/guidance/ph49.

5 Free C, Phillips G, Galli L, et al. The effectiveness of mobile-health technology-based health behaviour change or disease management interventions for health care consumers: a systematic review. PLOS Med 2014:10:1-45. 